\title{
Can social support work virtually? Evaluation of rheumatoid arthritis patients' experiences with an interactive online tool
}

\author{
Zlatina Kostova PhD, Maria Caiata-Zufferey PhD, Peter J Schulz PhD
}

\begin{abstract}
Z Kostova, M Caiata-Zufferey, PJ Schulz. Can social support work virtually? Evaluation of rheumatoid arthritis patients' experiences with an interactive online tool. Pain Res Manag 2015;20(4):199-209.
\end{abstract}

BACKGROUND: There is strong empirical evidence that the support that chronic patients receive from their environment is fundamental for the way they cope with physical and psychological suffering. Nevertheless, in the case of rheumatoid arthritis (RA), providing the appropriate social support is still a challenge, and such support has often proven to be elusive and unreliable in helping patients to manage the disease.

OBJECTIVES: To explore whether and how social support for RA patients can be provided online, and to assess the conditions under which such support is effective. An online support tool was designed to provide patients with both tailored information and opportunities to interact online with health professionals and fellow sufferers. The general purpose was to identify where the support provided did - or did not - help patients, and to judge whether the determinants of success lay more within patients - their engagement and willingness to participate - or within the design of the website itself.

METHODS: The present study reports qualitative interviews with 19 users of the tool. A more specific purpose was to elaborate qualitatively on results from a quantitative survey of users, which indicated that any positive impact was confined to practical matters of pain management rather than extending to more fundamental psychological outcomes such as acceptance.

RESULTS AND CONCLUSIONS: Overall, online learning and interaction can do much to help patients with the everyday stresses of their disease; however, its potential for more durable positive impact depends on various individual characteristics such as personality traits, existing social networks, and the severity and longevity of the disease.

Key Words: Chronic pain; Online social support; Pain management; Rheumatoid arthritis

Ora hronic pain sufferers with diseases such as rheumatoid arthritis (RA) feel stigmatized, lacking understanding and support from the surrounding social environment (1). Providing the right social support is still a challenge and such support has often proven to be elusive and unreliable in helping patients to manage the disease (2); however, it is crucial in helping them to accept the implications of the disease $(3,4)$. RA is one of the most prevalent causes of disability $(5,6)$ affecting approximately $1 \%$ of the adult Swiss population (7). More generally, approximately 1.5 million people in Switzerland are affected by some type of rheumatic disease and 300,000 are affected by a severe chronic form of arthritis and require constant care. RA has generated increasing costs for the Swiss health care system, and one in four disability pensions is paid for a rheumatic pathology (7).

In addition to the economic and physical toll, RA has many injurious psychological effects. Persistent pain, fatigue and progressive joint destruction invoke many disruptions and losses in patients' lives. RA

\section{Peut-on assurer un soutien social virtuel? L'évaluation des expériences des patients atteints de polyarthrite rhumatoïde au moyen d'un outil interactif virtuel}

HISTORIQUE : Selon des données empiriques solides, le soutien que les patients atteints d'une maladie chronique reçoivent de leur environnement est fondamental dans leur façon d'affronter les souffrances physiques et psychologiques. Néanmoins, en cas de polyarthrite rhumatoïde (PA), il demeure difficile d'offrir le bon soutien social, qui s'est souvent révélé évanescent et peu fiable pour aider les patients à prendre en charge leur maladie.

OBJECTIFS : Explorer si le soutien social des patients atteints de PA peut être assuré de manière virtuelle et comment il peut l'être, et évaluer les conditions qui rendent le soutien efficace. Un outil de soutien virtuel a été conçu pour fournir aux patients à la fois de l'information adaptée et des possibilités d'interagir par voie virtuelle avec des professionnels de la santé et d'autres personnes atteintes. Cet outil avait comme objectif général d'établir si le soutien assuré aidait ou non les patients et si les déterminants de réussite dépendaient davantage des patients, c'est-à-dire de leur engagement et de leur volonté à participer, ou de la conception du site Web. MÉTHODOLOGIE : La présente étude rend compte d'entrevues qualitatives auprès de 19 utilisateurs de l'outil. Elle avait comme objectif plus précis de présenter une explication qualitative des résultats d'un sondage quantitatif auprès des utilisateurs, selon lequel les répercussions positives se limitaient à des aspects pratiques de la prise en charge de la douleur plutôt que de toucher des aspects psychologiques plus fondamentaux, tels que l'acceptation. RÉSULTATS ET CONCLUSIONS : Dans l'ensemble, l'apprentissage et les interactions virtuels peuvent être très utiles pour aider les patients à vivre le stress quotidien de leur maladie. Cependant, leur potentiel de répercussions durables dépend de diverses caractéristiques individuelles, comme les traits de caractère, les réseaux sociaux déjà en place ainsi que la gravité et la durée de la maladie.

is both an unpredictable and invisible disease: the pain comes and goes and there are no manifest symptoms. Sufferers are, therefore, prone to be treated with scepticism and mistrust, and often complain of a lack of social support $(8,9)$.

The concept of social support - defined as resources provided by a network of individuals and social groups (10) - and its relationship with health has been faced by a burgeoning literature in the past 25 years (11-14). The multidimensional concept of social support typically refers to three groups - family, friends and significant others $(15,16)$ - and can include three basic levels - emotional, instrumental (helping hands) and informational (12). Definitional detail aside, there is strong empirical evidence that receiving social support may have both direct and moderating effects on health, increasing patients' empowerment and self-management skills, and buffering the negative impact of low health literacy $(14,17-20)$. According to the 'strain buffering hypothesis', social support can act as a 'direct agent' leading

Institute of Communication and Health, University of Lugano, Lugano, Switzerland

Correspondence: Dr Zlatina Kostova, Institute of Communication and Health, University of Lugano, Via Buffi 13, 6900 Lugano, Switzerland.

Telephone 41-58-666-4621, fax 41-58-666-4647, e-mail zlatina.kostova@usi.ch 
individuals to know that they are valued and loved, strengthening their self-esteem and, in turn, their health and well-being $(21,22)$. The moderating (indirect) effect of social support instead entails buffering the effects of stress on health. In other words, social support may act as a coping strategy that helps people to deal with stress and other threats to their psychological well-being.

The importance of social support for RA patients' health outcomes, coupled with the deficiency often felt by patients in that regard, means that health policymakers have sought ways to boost such support. However, the most intensive forms of social support are difficult to provide for cost reasons, and this is one reason along with the versatility of the Internet and the gradual breaking down of the 'digital divide' - why attention has recently turned to interactive online tools as a source of support for chronic pain patients. The questions of how to operationalize social support online and of what determines the efficacy of such support are at the heart of the present article.

There is literature that supports the Internet as an alternative tool of support for patients with chronic conditions (5,23-25). The virtual environment has the potential to impact decision making, sense of isolation or support, and adjustment to the illness $(26,27)$. 'Interactive health communication applications' are not only a means of exchanging information, but may also improve psychological, social and health outcomes $(8,28-31)$. In particular, it has been shown that online interventions can reduce bodily pain in adults with at least mild to moderate baseline pain (32).

In the terms of the health empowerment model of Schulz and Nakamoto (33), the Internet is a source of support that may impact patients' psychological empowerment and health literacy - two fundamental concepts for the self-management of chronic pain diseases. However, the impact of online social support on self-management cannot be taken for granted; it depends heavily on moderating factors such as the reliability of the information online, the nature of the illness, and various aspects of patients' perception of and experience with the disease $(34,35)$. For example, Caiata-Zufferey et al (34) have shown that chronic back pain patients' use of an online interactive tool depended mainly on factors related on their experiences with the disease, such as their previous awareness of the pain and their level of self-management. The study demonstrates that patients who were more experienced in the self-management of their pain were more selective in their use of the website, searching for tailored rather than experiential information from other users. Illness experience also plays an important role in terms of the impact of online support on health outcomes. In a similar study, Schulz et al (36) demonstrated that online communication demonstrated identifiable utility only for individuals who were already engaged in a process of self-management, improving their knowledge, daily management of the pain and the communication with their doctors.

Disease-related factors and psychosocial needs are other crucial elements affecting the type of the needed online support. Han et al (37) have shown that women with more advanced cancer used the interactive services of an online tool more heavily than women with an earlier stage of cancer. Cancer patients who already had experience with chemotherapy made more use of discussion forums and online peer support, while patients whose chemotherapy started after having joined the online tool preferred the static informational part of the site and expert communication. In addition, psychosocial factors, such as low social support and low quality of life, were fundamental, increasing patients' use of the interactive services rather then the pure informational contents. In this sense, people will access different thematic online content relevant to their disease journey according to their relevant disease experience, psychosocial needs and treatment events.

The desired amount and type of information regarding one's own illness may be restricted by patients' attitudes to the disease. In another study involving cancer patients, Leydon et al (38) noted that certain attitudes, such as hope, are maintained by silence; consequently, patients prefer to avoid certain information, especially when it is 'unsafe' and too detailed. This study shows how patients' attitudes to managing their condition may be restrictive, limiting sufferers from obtaining additional information about their disease.

The published literature on illness perception suggests that the individuals' perception of their risks with respect to the disease influences their information seeking and their participation in online communities $(39,40)$. It has been shown that factors such as the perceived susceptibility and the motivation to manage one's own disease are strong predictors that drive the use of health support groups as resources, which contributes to the health of the individuals.

Finally, the nature of the illness is another important factor affecting patients' search for online support. Previous research suggest that online support seeking is highest for conditions that are stigmatizing and stress-related (41-43). Although RA is not commonly considered to be a stigmatized disease in the literature, recent research shows that many RA patients actually feel embarrassed and negatively judged in their social environment for using the disease as an alibi to avoid responsibilities $(2,44)$. The unpredictable nature of RA is such that affected individuals are living in a constant state of uncertainty, dealing with the stress and the anxiety of the unknown evolution of the disease. For these reasons, offering RA patients a space where they feel heard and where they can share their concerns may be an additional support in dealing with the pain.

The abovementioned studies show how different disease and user characteristics affect the way individuals use Internet-based support systems, and the importance of tailoring online tools with consideration of these factors. Nevertheless, existing research is limited in scope in some important respects. First, research attention has turned mainly to explain the effects of virtual interaction and patterns of online use. Little research exists exploring the antecedents of online community participation in the context of chronic pain. Some of the quantitative studies investigating the utility of online support show mixed results $(36,45)$, and there are no such studies focusing on RA patients, which is important because of the difficulty in obtaining trust and support in one's real social environment using the 'traditional' routes. The ephemeral and invisible nature of the symptoms of RA make it difficult to be understood by significant others such as family members, friends and doctors. Providing RA patients with the appropriate support in their real social environment may, therefore, be a difficult task to achieve (44). For this reason, investigating how to offer social support online can be an alternative method to compensate for the missed 'offline' support among RA patients.

Second, there is, to our knowledge, no in-depth research explaining why the effectiveness of Internet-based approaches is mixed, and why it works sometimes and for some people but not for others. This is why it is important to explore qualitatively how and why online support works in helping people to manage their pain, identifying the factors that can maximize the effectiveness of such support. Indeed, in the present article, we propose to explore the underlying reasons that drive the use of an online interactive tool purposely designed for RA patients.

The present study forms part of the evaluation of an online social support project financed by the Swiss National Science Foundation. An interactive website called Oneself (www.oneself.ch) provided RA patients with personalized information and the possibility of communicating online with health professionals and other patients. The empirical basis for this article is a qualitative evaluation of Oneself based on in-depth interviews with 20 users. Our two core research questions are cumulative: which factors shaped patients' willingness to engage with the site and interact with other users; and under which circumstances was this engagement more successful in delivering positive health outcomes? Put simply, we aimed to determine what led people to use the tool, and what enabled them to profit from it. For the latter question in particular, we were guided by insights from a previous experimental study of Oneself users, which indicated that the tool helped more with everyday pain management than it fostered deeper psychological outcomes such as acceptance (45). The aim of the 


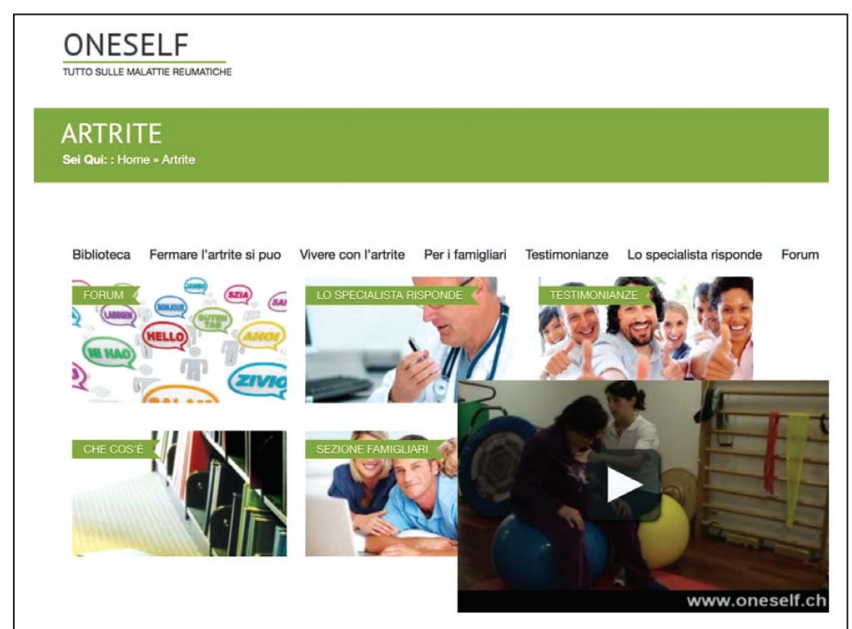

Figure 1) Informational section

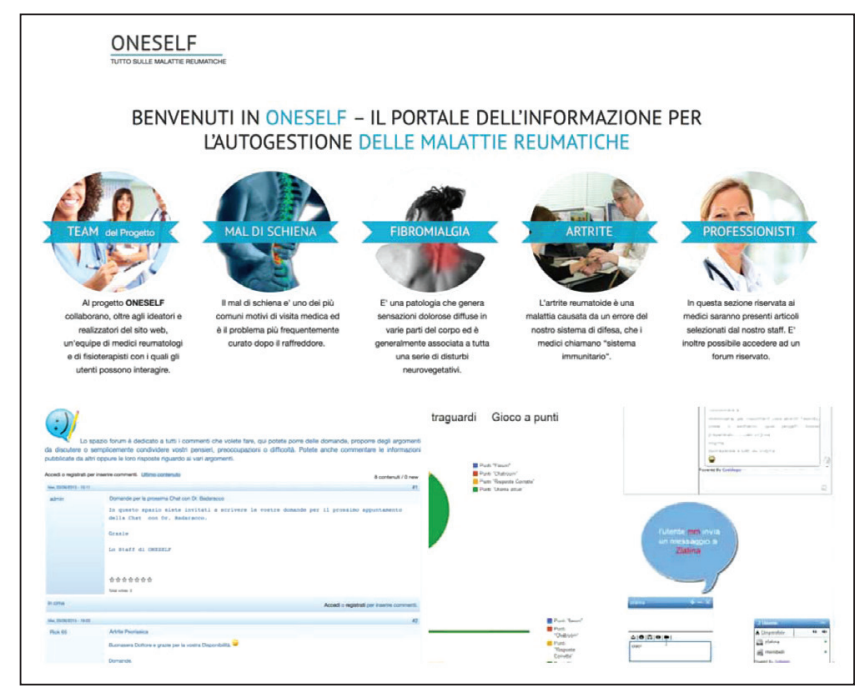

Figure 2) Interactive section

are the objective exchange of resources; however, a patient's satisfaction with these exchanges depends on his or her needs and expectations according to the specific situation. More or less explicit in that definition is the notion that social support itself may not always be satisfying for patients and, in turn, that it is important to understand sufferers' specific needs and difficulties with their disease to provide them with the appropriate type and amount of support. This is the reason why, before creating Oneself, the authors first considered the patients' point of view, exploring the main difficulties they faced during the internalization of the disease.

The structure of Oneself was also guided by the theoretical model of Schulz and Nakamoto (33), which distinguishes two components of health empowerment: health literacy (factual and procedural knowledge about how to deal with the disease) and psychological empowerment (feeling able to deal with the disease). Consistent with and reflecting this distinction, Oneself provided both informational and interactive opportunities for users.

The informational part of the site (Figure 1) was divided into sections according to the key problems identified in the previous interviews. For example, it became clear that late diagnosis - often following a period of scepticism and distrust of general practitioners was common and had many negative physical and psychological effects. Therefore, a section referred to as 'the Library' was created in which information was provided emphasizing the importance of early diagnosis and the recognition of the first symptoms, as well as other educational material about the nature, etiology and evolution of the disease. Another example of providing tailored support concerned common postdiagnosis reactions such as denial, self-isolation, anger and depression. These were examined in the section on living with arthritis, which not only informed patients about the negative consequences of these reactions but also gave advice about more appropriate strategies for confronting and accepting RA. Addressing one key aspect of the social support deficit, a section entitled 'Family' was created, with suggestions about what patients need in terms of support and how to avoid conflict dynamics. These sections were not confined to text information; there were also videos presenting advice on, for example, occupational therapy and physical exercise. The aim of all of this informational support was to boost patients' health literacy and, in turn, their constructive self-management behaviour.

The interactive part of the website (Figure 2) provided opportunities for interactions with experts and other patients online, enabling users to receive the support that they were missing in their real life. There were weekly meetings in a chat room between patients and various experts (rheumatologists, physiotherapists, occupational therapists 
TABLE 1

\section{Characteristics of the sample $(n=19)$}

\begin{tabular}{|c|c|}
\hline & $\mathbf{n}$ \\
\hline \multicolumn{2}{|l|}{$\overline{\text { Sex }}$} \\
\hline Female & 11 \\
\hline Male & 8 \\
\hline \multicolumn{2}{|l|}{ Age } \\
\hline $30-39$ & 4 \\
\hline $40-49$ & 5 \\
\hline $50-59$ & 5 \\
\hline$\geq 60$ & 5 \\
\hline \multicolumn{2}{|c|}{ Time since rheumatoid arthritis diagnosis, years } \\
\hline $5-9$ & 5 \\
\hline $10-15$ & 5 \\
\hline $16-20$ & 5 \\
\hline$\geq 20$ & 4 \\
\hline \multicolumn{2}{|l|}{ Level of education } \\
\hline University degree & 4 \\
\hline High school/professional school & 10 \\
\hline Middle school & 5 \\
\hline \multicolumn{2}{|l|}{ Marital status } \\
\hline Married & 12 \\
\hline In a relationship & 3 \\
\hline Widowed & 2 \\
\hline Divorced & 2 \\
\hline \multicolumn{2}{|c|}{ Informational usage (number of pages accessed) } \\
\hline High $(\geq 40)$ & 10 \\
\hline Moderate/low (<40) & 9 \\
\hline \multicolumn{2}{|c|}{ Interactive usage (number of chats participated in) } \\
\hline $\operatorname{High}(\geq 6)$ & 11 \\
\hline Moderate/low (<6) & 8 \\
\hline \multicolumn{2}{|c|}{ Impact of the website on health outcomes } \\
\hline High & 7 \\
\hline Low & 12 \\
\hline
\end{tabular}

and psychologists) that discussed topics relevant for patients but seldom discussed during formal medical consultations. One of the authors of the present article was the coordinator of the website and was available online throughout these chats, moderating the discussion and encouraging users to interact. To persuade patients to establish new networks and to support one another, a private chat was created in which patients could contact one another confidentially, outside of the official meetings. Another section, the 'Forum', enabled asynchronous interactions - users could post questions and comments and await answers from both doctors and other patients. Other examples of interactive support are 'My contribution' (practical advice posted by users), 'The specialist responds' (video interviews with health professionals about patients' major concerns) and 'Testimonials' (interviews with patients about their struggles). Collectively, the interactive elements of the site aimed to empower patients in two ways: by making them feel supported and listened to by professionals, and by bringing them into a virtual community of fellow patients dealing with the same physical and psychological problems.

\section{Evaluating the Oneself project}

In the project as a whole, a mixed-methods approach was used; ie, patients' use of the tool and its effects on key health outcomes were studied both quantitatively and qualitatively. In the first stage, an experimental study was conducted involving 154 RA patients recruited through the health professionals involved in the project. Approval was obtained from the Ethical Committee of Canton Ticino (the Italian-speaking part of Switzerland), and patients who agreed to participate signed a consent form and sent it to the
University. Eligible for the present study were patients with RA who had cognitive function sufficient to use the website effectively, who did not suffer from other major chronic illness (eg, cancer, diabetes), and who agreed to $1 \mathrm{~h}$ to $2 \mathrm{~h}$ per week of 'log-on time' over a total period of eight weeks. These patients were randomly assigned to two experimental groups with different access to the various sections on the site. One group had access to both interactive and informational sections, while the other had access only to the informational part and a control group had no access to the site at all. The aim of the quantitative study, as mentioned above, was to assess the effect of the website on various health outcomes such as psychological empowerment, perceived social support, health literacy, acceptance of pain, quality of life, self-efficacy, health care utilization, medication misuse and physical activity. A summary of the results is presented in the Results section, evidencing their mixed character. These mixed findings guided the motivation of the qualitative study to identify the factors and circumstances that determine the efficacy of social support online.

For the qualitative study, in-depth interviews were conducted with 19 patients from the group that had had access to the interactive part of the website. From a total of 54 users, 15 were excluded because they did not meet the inclusion criteria described below. Thirty-nine users were contacted by telephone; 31 answered. Of these, 20 agreed to be interviewed immediately. Eleven refused to participate because they did not have time, lived too far away from the University or were not interested. One of the users dropped out just before the interview; thus, the final sample included 19 participants. To maximize the range of respondents' experiences with the website, the authors ensured a diversified sample in terms of sex, age, length of RA diagnosis, level of education and frequency of use of the website.

Details of the participants are in Table 1, which include demographic and medical characteristics as well as variables related to experience with Oneself that were also considered in recruitment: the extent of participation in both the informational and interactive elements of the site, and the extent of improvement in health outcomes as a result (more and less active users were selected, as well as users who improved or did not improve in health outcomes). The latter is based on calculating, for each patient, the average in his or her changes across all the health outcomes measured. Selecting according to these criteria facilitated the comparison necessary to answer the two core questions of the present study: which factors encouraged people to participate or to stay away, and under which circumstances did participation translate into positive outcomes?

To elicit patients' views about what engaged them to interact with and use the site, a flexible interview guideline was prepared, beginning with general questions about their opinions of Oneself and then moving on to more specific topics about what motivated them to interact online or discouraged them from doing so. Interviews were conducted at the University of Lugano and lasted approximately $1 \mathrm{~h}$.

Data collection and analysis were conducted simultaneously and performed in cycles. Interviews were tape-recorded and transcribed. The constant comparative method (47) was used to code each interview, to link and group the identified codes into larger categories, and to define more abstract concepts around which to organize the various arguments. These operations allowed for reduction and interpretation of large amounts of data, and continued until signs that data saturation was achieved. Some commonalities in patients' experiences were observed even during the early interviews. As interviews continued, key factors could be identified, most of which were common to most patients. By the final interviews, signs of data saturation were observed - ie, patients were tending to describe the same views and factors (although not necessarily all in the same order). The analysis of the initial interviews informed the discussion in the subsequent interviews. Literature was also used throughout the research to support the process of questioning and interpreting the data. During the transcription process, personal data were removed and fictitious names were attributed. 
Each interview was examined and read many times by the authors to identify links among the retrieved categories. This enabled the identification of possible conceptual themes that the authors discussed several times, solidifyingy certain common themes. The results discussed in the present study are the outcome of this continual and iterative to-and-fro process, and the present findings constitute a reasonable representation of the studied phenomenon (48).

\section{RESULTS}

Quantitative analysis: the effects of Oneself on patients' health outcomes

Before examining the interview data in detail, it is useful to set the context for those follow-up interviews by briefly reporting the mixed quantitative results from the experiment. These can be usefully summarized by the $t$ tests presented in Table 2. Each $t$ test indicates whether participants showed a significant improvement between the pre- and the post-test questionnaire for that indicator. There was no appreciable improvement in several of the key variables measured in the survey. However, there are exceptions and these can be seen as falling into a pattern. Significant improvements occurred on variables that are more concrete than abstract. For example, there was an improvement in health literacy - measured by a quiz of knowledge of RA - and there was a particularly clear reduction in patients' immediate concerns and distress about the evolution of the disease. In contrast, there was no change in deeper self-perception variables such as acceptance and empowerment. In other words, the experiment was able to influence patients' everyday experience of the disease, but was less successful in altering their mindset with respect to the disease.

Qualitative analysis: determinants that impact the use of online social support

Considering the mixed quantitative results, some of the main factors that affected patients' use of the site that may explain the impact of Oneself on certain variables and not on others will be discussed.

In the theoretical section (see Introduction), some factors that moderate the effectiveness of the received social support were defined: the characteristics of the Internet source (eg, credibility); patients' internal and external experience with the disease; and illness dimensions. The Results section is organized with consideration for these subheadings, identifying from patients' points of view the things that affected the way they interacted online - what triggered them to seek online support, and to participate in the interactions.

Internet-related characteristics: Undoubtedly, the design, structure and offering of the site were fundamental to patients' motivations for using it. More precisely, the double interaction with doctors and patients, the reliability of the source, anonymity and the presence of a moderator were all elements that patients mentioned as important for their online participation.

The double interaction: All of the interviewees indicated that the key incentive for interacting with the website was the official weekly meetings with the doctors and with the patients. This double interaction was viewed as a 'golden chance' both to obtain immediate professional advice and to access real examples of how other people deal with the disease. Online communication with both experts and patients helped sufferers to 'calm their worries' and, in turn, to better manage the stress of the disease. The resulting 'exchange of ideas' also helped patients to become more confident in understanding the disease:

A website like that is a real help because it's a way to exchange ideas thanks to the others' experiences. Especially benefitting from the doctors and taking advantage of their experiences, calming your worries, your anxiety, you better understand your disease. For me it was a mixture of two things: the side that gives you the answer - the doctor, the professional experience; and on the other hand to see the experiences of who is suffering in the front line. It's a fusion of the two things - having an answer and understand the solution, and that helps you a lot to overcome your fears, your concerns... (Riccardo, 45 years of age)
TABLE 2

Mean differences in various dependent variables among experimental participants (paired samples $t$ tests, $n=113$ )

\begin{tabular}{lccc}
\hline $\begin{array}{l}\text { Dependent variable } \\
\text { (range of response scale) }\end{array}$ & $\begin{array}{c}\text { Pretest } \\
\text { mean }\end{array}$ & $\begin{array}{c}\text { Post-test } \\
\text { mean }\end{array}$ & T statistic \\
\hline Social support (1 to 7) & 5.49 & 5.36 & -2.04 \\
Acceptance (1 to 7) & 4.73 & 4.63 & -1.54 \\
Psychological empowerment (1 to 7) & 5.07 & 5.13 & 0.48 \\
Stress management (1 to 5) & 3.23 & 3.49 & $4.10^{\dagger}$ \\
Pain management (1 to 11) & 6.81 & 6.94 & 0.69 \\
Health literacy (0 to 15) & 7.42 & 7.75 & $1.75^{*}$ \\
Self-efficacy (1 to 11) & 6.64 & 7.14 & $3.11^{\dagger}$ \\
\hline
\end{tabular}

${ }^{*} P<0.1 ;{ }^{\dagger} P<0.01$ indicate significant improvement

Putting concerns into words was also a way for patients to give a form to the disease and also to reframe it, considering it in a different light. As one patient pointed out, the online chats could not solve their problems but helped them to 'visualize' the pain and to 'discharge' the concerns, which was helpful to deal with the physical and the psychological impact of the disease:

It is like talking with a friend: is not that they solve you the problem, but it helps you to release all that you have in your head. And those chats helped me a lot in that - to reformulate my thoughts in sentences and to put them in order, to give them a form. These chats simply help you to re-dimension everything, you put it in a frame. So you start visualizing that pain finally... (Angela, 55 years of age)

The reliability of the website: The fact that the website was managed by the University and by recognized health professionals made it a credible and reliable source. This increased trust in and, thus, use of the site. The online presence of the doctors was viewed as a guarantee of the trustworthiness of the available material - thus avoiding the risk of erroneous information that other medical websites may invoke. One patient, who had already had some negative experiences with online information, trusted Oneself because:

There is less risk of errors. If I enter in a random RA site I cannot make questions to the doctors - I must be able to understand alone the information and I may make some error, as I did in the past. Instead here (on Oneself) you can interact and understand immediately what is right and what is wrong, asking the doctors. (Andrea, 43 years of age)

The trustworthiness afforded to the site by the presence of health professionals was clearly an incentive to interact and reinforced the value of the double interaction discussed above:

I found it extraordinary that during those online exchanges there was also a specialist. As a consequence the value of the site is double: you have the exchange with the patients and then you have the specialist who answers you. (...) This is important to me, because in that way you instantly clarify the things with somebody who is an expert, it gives you more trust to interact. (Virginia, 72 years of age)

The fact that the site was developed locally and featured nearby professionals brought it closer to patients' reality, another factor that encouraged interaction:

You feel it [Oneself] more close to you, because it's Swiss, I trust it more...when you read the names of the doctors and if you have some question, you just know that they are here and you can contact them. (Livia, 42 years of age)

The anonymous interaction: The anonymity of virtual interaction had an ambivalent affect with respect to the different stages and levels of communication. When it came to medical advice during the 
official chats, virtual communication helped patients to interact with doctors because it made them feel free from the responsibility and rules involved in face-to-face interactions. The privacy of the online chats buffered the 'direct confrontation' in a way that facilitated interaction:

Online you don't have to show up physically, even if the disease is not visible, but in any case online there is no this direct confrontation. I would feel much more embarrassed to participate in a real meeting, but if there is another one online with the experts I would participate with pleasure. (...) in a real meeting you cannot be mute, instead on the computer you can also not write if you don't want. And I think that this helps you to start chatting, especially for somebody like me who is not used to that. (Nicole, 42 years of age)

Another patient agreed that the anonymity helped to 'get the interactive ball rolling':

You have the anonymity online - you are there, but at the same time you are not. And so you let flow the words in a different way, especially during the chats with the doctors I found it more easy to start. (Angela, 55 years of age)

Anonymity thus facilitated the initializing of communications, especially with doctors, during the official chats and the discussion of more practical issues. However, when it came to the possibility of patients opening up on a deeper and more personal level, interviewees cited the virtual and anonymous nature of interaction as a hindrance rather than a help. This helps to explain why, once the official chat with the experts was finished, almost nobody took the initiative to contact somebody else and to continue the interaction on a more personal level. As one patient put it:

If the aim of the site was to create a kind of union between patients, I don't think it was very successful... there was not that interaction only between us - we were talking or with the doctors or with you. (...) It is already difficult to talk about your personal stuff. So why I should open myself with somebody that I don't even know? (Livia, 42 years of age)

Another interviewee highlighted the need to establish visual contact with unfamiliar others.

Sometimes you need to see the face of the other, the facial expression, I need the visual contact. Especially when you are going to talk about personal things. And maybe this is the point where the computer blocks me - if I am going beyond a certain level, I need to see, to feel the person. You know, opening yourself completely without seeing the other one is not so easy. (Christiane, 60 years of age)

The moderator: Several patients highlighted the moderator as an important incentive to interact. The moderator served as an important intermediary between doctors and patients, 'introducing' the latter to the former and encouraging patients to put their particular questions to the expert. In addition, the moderator was someone who steered the conversation and helped to maintain focus on the specific topics in chats that may otherwise have petered out, gone off on tangents, or been hijacked by one particularly vocal participant. One patient appreciated this direction:

I think that your [the moderator's] role was very important because you were intervening when the discussion was wandering off $[\ldots]$ There are plenty of other places online, like Facebook or some forums, where you can talk about whatever you want, but these meetings [on Oneself] were on a specific topic and I think it's important to have a coordinator. (Gerardo, 60 years of age)

In the case of Oneself, the chats were moderated by the same person who had made a personal contact with each of the patients during the recruitment process, and this helped to provide some familiarity within an otherwise unfamiliar network:
You were our guide, otherwise I wouldn't have participated. The fact that there was a connection with you, that you were somebody who had convinced us to participate in the first place, was important in getting us involved. (Nicole, 42 years of age)

Disease dimensions: Of course, use of a tool like Oneself is driven not only by the design of the site but also by their experiences with the disease such as level of disability, time of suffering and the specific nature of the illness. All of these influenced both the way in which patients approached the virtual communication and their capacity to profit from it.

Time of suffering and pain severity: Some key aspects of patients' RA experiences, such as time of suffering and the severity of their condition, influenced their need for online support and their engagement in the virtual interaction. In particular, those currently passing through an acute episode of pain were in need of online support:

When you feel well, it's easy to not think about it (RA), but when you feel pain, the more symptoms and problems you have, the more probable it is that you need to navigate, to talk with somebody who makes you feel better. (...) That's why, when you invited me to participate, it was a very difficult period of time, so I was needing it much. (Elena, 39 years of age)

Meanwhile, patients who felt less impacted by RA also then felt less entitled to give advice to and to interact with those more heavily affected by the illness. That was one reason why some patients were more passive during the online chats:

Maybe the level of my disease is not so serious and that probably stopped me contacting somebody else. I felt myself involved, participative but in a more humble way, less strongly than the others. One of the reasons of my participation for me was also to help the others, I mean - are the questions that I ask useful for the others? Because who am I in front of somebody who cannot stand up or is in a wheelchair? My pain was ridiculous in comparison with the others, so what experience could I bring? (Roberto, 65 years of age)

Also another participant, explained his passiveness during the chats with his lower intensity of pain:

I don't know, luckily I don't have a strong pain, so I probably didn't need these chats, I don't know what to say..it was interesting to read what the others said, but I never suffered from such a pain, so I didn't have such a big experience to bring up. (Antonio, 65 years of age).

Nature of the disease: Many people complained about the fact that the nature of RA is such that symptoms are totally unpredictable and pain can suddenly appear and disappear without any reason. This unstable character of the disease made patients live in a constant state of uncertainty and stress, without knowing the future evolution of the disease and what will happen with their bodies the day after. That was a reason why some of the participants - especially the ones whose acute episodes were strongly disabling - were more interested in accessing the website and learning something more about the management of the disease. The unknown causes and future of the disease made some people more interested in the informational and practical support offered online:

It is [RA] a difficult disease, because you don't know what will happen with you tomorrow. Today you feel good and tomorrow you cannot get out of the bed. For me the presence of the doctors on the website was very helpful, because when you are sick and when you have the doctors on the other side, you start asking a lot of questions. You ask if it [RA] can affects your heart, your vital organs..because you are afraid, you accept the illness, but you don't accept to die. (...) That's how it (Oneself) helped me when you go to the doctors they will never tell you what is the cause of this disease and what your future will be, whereas under the form of a chat online I've tried to ask questions to get in a 
better mood and to be more serene with my negative thoughts. (Gerardo, 60 years of age).

Internal and external experience with the disease: In this section, how use was shaped by patients' psychological experience of their disease, the reaction of their social context and social network, and their broader behavioural styles will be discussed. All of these influenced both the way in which patients approached the virtual communication and their capacity to profit from it.

Psychological dimensions: Experience of the disease also has its psychological component. The way in which patients perceived the disease, and also their level of acceptance, influenced their use and need of virtual communication. For those who were avoiding and denying their condition, interacting online was seen as a reminder of the problem they wanted to avoid and so they were more reluctant to chat. As one patient admitted:

I don't accept this illness, I am telling myself that I don't have it. I know it sounds weird, but this is my way to face it. So meeting people online who are talking about the pain and about things that I want to avoid is a bit useless for me, it's like you make official your status as a sufferer. (Morena, 35 years of age)

In contrast, for those who did not perceive their disease as a taboo, Oneself was viewed as a source of practical assistance in facing the illness. These patients were not only more open toward alternative methods of support, they were also more willing to share their experiences:

For me my illness is not a taboo or a reason to be ashamed. I think that the openness, the encounters with the others cannot be other than a positive benefit. So I've never experienced my illness as a closure or as a fear to show it to the others - it's exactly the opposite, it's something that I'm happy to share! I pass on my experience and I want to learn from the others' experiences too, because I can only benefit from that. (Martino, 53 years of age)

Social dimensions: Another factor that affected patients' virtual interaction was the way in which their disability is treated and recognized within their (real) social environment. Patients who did not feel particularly well understood by their surrounding environment were the most willing to interact and to seek virtual support. For these patients, the online space was offering them the consideration that they were missing in real life. The anxieties that could be externalized during chats might otherwise have no outlet:

It (Oneself) helped me to bring out all the anxiety of my disease, my neurosis...to have the chance to talk about my illness, to feel considered first of all... Because don't forget one thing: when you are outside, when people look at you and tell you: "Go to work, instead of stealing money from the health insurance!" It's not nice... Even when you talk with your nearest, they tell you that you don't have any disease. And also with your doctor is the same - I don't want to play the victim, but from my experience during some medical visits, you feel like you are more like a burden. Instead on the website you talk with one doctor and you ask a question, then you maybe ask another question, and so on..it helps to calm your mood and get rid of what torments you... (Gerardo, 60 years of age)

The nature of patients' social networks influenced not only the extent but also the nature of their participation. Naturally, people who had a satisfying and rich network, and who, thus, already felt a sense of social support, were particularly disinclined to establish new personal contacts or to enter into deeper levels of interaction with the other patients. They instead perceived Oneself as a means of obtaining practical advice. This again helps to explain why the site had less success in creating an online community on a lay level:

I was going online especially for the meetings with the doctors. It's not that I was not interested to see what the others write, how do they live with the disease - this is interesting, but it didn't give me the push to say "ah, I really want to establish a contact with that person!” Then I have also my friends, I have many people coming to visit me at home, I have many contacts - so this kind of saturation probably made me less willing to go on a deeper level...but for people who don't have a lot of friends, I bet that it [Oneself] is ideal! (Marlene, 48 years of age)

Behavioural styles: Even if it cannot be assumed that personality is a main predictor of online behaviour, some broader behavioural styles and attitudes were observed to impact patients' online engagement. Indeed, online behaviour was generally reflective of the way that people interacted in real life. Two particular types of participant were observed: the 'lurkers', who were more passive and were mainly reading the others' comments; and the active users who were readier to use the chats, forums and other interactive parts of the site. These two categories were strongly connected with the real-life behaviour of the participants: active users then described themselves during interviews as more open and sociable in real life, while lurkers tended to be shy in interviews and elsewhere. As one patient described it:

It's a question of who you really are, I think it's as when you are in a real group: there is who is listening and who is talking; there are these two categories. It's a question of personality. But those who are just listening, it doesn't mean that they don't have anything to say. May be they are more introvert, more shy. I am more open, I am not reserved, but there are others who are different. I think it's a matter of character. (Benedetta, 58 years of age)

One of the participants explained her infrequent intervention in the chats by her introvert and reserved personality:

I liked the chats, even if I didn't say so much. I am not a great chatterer, I don't freely chat with everyone. I am more listener than orator. I keep my things inside, I don't like to share them so much, but also only reading the others, you recognize yourself in their stories. (Marlene, 48 years of age)

\section{DISCUSSION}

The present study explored patients' perspectives on the capacity of a tool such as Oneself to deliver social support online. Even if we expect that online engagement will increase with the emergence of online support tools, recent studies - including the present study have indicated that few patients actually engage in virtual support interactions $(34,49,50)$. In this light, we can deduce that there are some important determinants affecting patients' health-related Internet use. Some contradictory findings are present in the literature: while some studies explained online engagement only with sociodemographic characteristics, others indicate mainly psychosocial factors as stronger determinants (51-53).

With regard to psychosocial factors, it has been shown that some constructs, such as levels of functioning, sense of self efficacy, emotional well-being and social support, are all relevant to patients' online seeking behaviour (54). Psychosocial characteristics may also determine patients' online seeking in terms of forms of support, including didactic, narrative, peer or expert based. Results from previous studies involving Oneself show that people preferred sections that allowed for asynchronous interaction with experts (36). On the contrary, sections encouraging lay and synchronous interactions were used less. The same study points out that expert interaction was appraised as an efficient means of obtaining high-quality and tailored information in an autonomous and convenient way, while lay interaction with peers was perceived as a risky and demanding form of communication.

Our participants confirmed these findings, pointing out that Oneself was used mainly because of the presence of doctors and users were much less interactive on a lay level. Echoing the quantitative study cited earlier, our interviews emphasized that Oneself helped patients more on a practical level, boosting their capacity for everyday management of the disease and, thus, aspects of their quality of life. It was less successful in changing deeper mindsets such as perceived 
social support, acceptance and empowerment. The interviews also provide a convincing explanation for this difference. Oneself was perceived as a tool for obtaining professional advice and learning about how others deal with the disease, but not particularly as a network for interpersonal interactions or support. Returning to the health empowerment model (36), it is clear that patients were more open to the facets of Oneself that were likely to help with the health literacy component of the model.

In light of this, it is not surprising that the quantitative study showed this intervention to have a positive effect on stress management. In fact, discussions with and advice from medical professionals helped patients in areas such as pain and distress. In contrast, patients made less use of the interactive opportunities that were designed particularly to impact on the psychological component of the model, such as the lay interaction with peers on the chat or the use of the forum. Even if users turned to the interactive sections, it was mainly restricted to the 'official' chats with the doctors to obtain medical advice, and they avoided sharing their concerns on a lay level with other patients. In this light, it was a question of the purpose of the interactions, which were mainly focused on more technical issues and conducted exclusively with the doctors. Because the tool did not become a space for intensive interaction, it was less able to impact mindset variables.

In patients' eyes, the strongest inducement to engage with Oneself was the double interaction with doctors and patients, where the availability of doctors was the leading reason for access. The moderating role played by health professionals, and especially their role in the organized virtual meetings, allowed patients to share their concerns and to benefit from both expert advice and the real stories of other patients in their position. During chats, patients felt considered and listened to, and interacting online was a way to articulate and externalize their problems. Several patients remarked on the way in which these interactions eased their fears about the future evolution of the illness, which helps to explain why the quantitative analysis revealed stress management to be one variable on which Oneself had a reliably positive impact. Returning to the stress buffering hypothesis $(21,22)$, we can confirm that the main outcome of our operationalized online form of support was to buffer the stress related to the unpredictable evolution of the disease. Even if our website was less successful on a lay level, it offered the possibility to express and share the concerns and the anxiety of the unknown future with experts. These results are also aligned with those of a parallel study involving chronic back pain patients, in which chats with experts were highlighted as crucial to the virtual interaction that helped users to "construct their personal frame of reference about the nature and the course of their disease" (36).

Meanwhile, the failure of Oneself to create a virtual space for lay support among patients could be partly explained in respect to some determinants. It was shown that many patients are unaware of support groups and that lay interaction is impeded by some misconceptions, such as the misconception that only severe, older and lonely patients or those unable to cope with their illness engage in support groups (55). Fears of being emotionally overloaded or of becoming confused with further information are other barriers to virtual peer interaction $(34,55)$. Also, some of our participants expressed their skeptical perception of the chats as a place where people mainly complain, and this idea impeded their engagement in virtual interactions.

The lower interaction on a peer level in our case could also be explained by some cultural aspects of the context of the present study. Surveys indicate that the Internet is not widely used in Switzerland as a source of support: only $10 \%$ of patients reported seeking health information and help online and, in the Italian-speaking part of the country, this proportion was even lower $(23,56,57)$. The corresponding figure in other European countries was $30 \%$ and in the United States was as high as $40 \%$ (23). This is not because Internet penetration levels are any lower in Switzerland; it just seems that the Swiss are less likely to have recourse to online health support. Rather, for them, physicians still represent the preponderant and most trusted resource of health information. So the notion of a virtual community involving only patients was not seen as a sufficiently reliable source of support $(56,58)$.

While previous studies highlighted the facilitating role of anonymity in online interaction among chronic patients (41), in our study, anonymity had an ambivalent effect in relation to the nature and the stage of the communication. Initially, privacy and invisibility were indeed enabling factors, leaving patients feeling freer and less judged during the official chats with the doctors. However, when it came to deeper interpersonal interactions, the lack of real and visual contact with others deterred patients from opening up and sharing their problems - this again helps to explain why our intervention was less successful on a personal and psychological level.

Patients also believed that their online behaviour was reflective of their broader styles of interaction in real life. Patients who perceived themselves as generally more open were the ones who were more interactive during the chats, while those who self-identified as more reserved were also more passive in Oneself. Other studies find similar results: for example, the phenomenon of 'lurkers' online has been shown to reflect similar behaviour in real life (35). Passive online members may select a low level of visibility and participation as their preferred method of functioning in any group situation, whether face-to-face or online. Compared with lurkers, active online members visit online support groups more often for social reasons, such as curiosity, to enjoy themselves and to offer their expertise (49). Reasons for being more passive online and 'lurking' include concerns for privacy, no need to post, respect for others' time and lack of fit with the dynamics of the group (59). In addition, in our study, people who were less active during the chats referred their passiveness to personality reasons (such as being shy and less social), but also to reasons related to the disease such as lower levels of pain and consequently less need to share their concerns. The literature confirms these findings, indicating that lurkers typically have a shorter disease history (49) and that shy online members may prefer to lurk until they understand the online group's norms and style $(60,61)$.

The problem here is that general behavioural style may also predict patients' need for social support. If those who are more reserved also struggle to build and maintain a supportive social network in real life, then the least active users of Oneself may have been those who were most in need of what it could offer.

Of course, patients' need for and modes of interaction also depended on their specific experiences of RA in themselves and their lives. Acceptance of the illness was often a precondition of being more open in sharing the disease and searching for alternatives of support; patients who were still in a stage of avoidance or resistance were less willing to talk about their pain. The literature clearly shows that acceptance plays a positive role in patients' physical, social and emotional functioning, and that those who come to terms with pain report greater confidence in their coping ability $(62,63)$. Other studies have confirmed that individuals with a deeper awareness of their disease benefit more from online support, using it in a more personalized and selective way for their particular needs (64). In our study, acceptance mainly mirrored the way patients perceived the illness. Some of our participants continued to perceive their disease as a stigma or as a taboo, feeling uncomfortable of being judged as different by others and not accepting the limitations of the pain. As above, one unfortunate implication of this pattern is that online social support may be of least use to those who need it most.

Together with internal experiences of the disease, patients' external or social experience of RA was an important factor that affected the need for online support. Patients most eager to participate in online forums tend to be those with conditions that are misunderstood or stigmatized by wider society (35). RA patients often complain of a lack of understanding or trust from their significant others, whether family members or medical professionals, and some perceive prejudice as well (44). It has been shown that patients who experience negative social reactions to their disease tend to internalize the stigma in a way that weakens their sense of personal control over pain and leaves them prone 
to catastrophizing (65). Indeed, in our study, it was exactly those users who felt stigmatized and unsupported by their social context who were the most engaged in the Internet discussions, where they felt considered and understood without conditions. This leads to a more optimistic conclusion than that which closed the previous paragraph: in this case, the support gets to those who need it most. That same conclusion is suggested when the longevity and severity of patients' conditions are considered, both of which shaped patients' online behaviour. Patients who had greater control over their disease and who did not experience acute episodes of pain did not believe that they were in a position to interact with and to advise others who were more heavily impacted. This reinforces the findings from previous studies that patients who have had a disease for longer and who experience it more severely are the ones who benefit more from virtual support $(34,53,66)$.

Despite the limited success of Oneself to create a virtual community, we should conclude our discussion of the study on a more positive note. Although we have focused on barriers to participation and difficulties in bringing about genuine online interactions, we should emphasize that Oneself also generated several of the positive effects that were reported by others attempting to deliver social support to patients online. Social support online provides specific benefits such as the absence of geographical barriers, $24 \mathrm{~h}$ availability, reasonable costs and anonymity (67-69). Another advantage in participating in online support is that people can reach a wider range of peers and thereby gain access to even more information without leaving their homes (70). In the case of RA, in which acute episodes of pain disable patients, being able to receive information and support directly at home may be helpful. In spite of the Internet's vast potential for health care, websites for chronic pain patients are restricted to provide only general information and advice, which often does not meet people's specific interests and expectations (71-74). We attempted to overcome these limitations and successfully created a tool that provided a specific type of patients those affected by RA - with tailored information and the actual presence of experts and peers. Overall, we saw that online support cannot be applied automatically, but rather has to be tailored with patients' needs and expectations. The strongest advantage of Oneself is that it provides patients with practical material, based on sufferers' needs. It is also monitored by health professionals, which represents a strong incentive and motivation to engage in online communications. Another feature of our website was the presence of a moderator who was the 'bridge' between patients and the doctors and who guided the chats into the right direction. The presence of a moderator who establishes a personal contact with the patients and invites them to participate is a strong motivator to people to feel engaged and cared for. In this light, providing support means not only speaking about some kind of disease, but speaking with the patients and making them feel supported in their specific needs and difficulties.

\section{REFERENCES}

1. Davison KP, Pennebaker JW, Dickerson SS. Who talks? The social psychology of illness support groups. Am Psychol 2000;55:205-17.

2. Kostova Z, Caiata-Zufferey M, Schulz PJ. The process of acceptance among RA patients in Switzerland: A qualitative study. Pain Res Manag 2014;19:61-8.

3. McCracken LM. Social context and acceptance of chronic pain: The role of solicitous and punishing responses. Pain 2005;113:155-9.

4. Revenson TA. The role of social support with rheumatic disease. Baillieres Clin Rheumatol 1993;7:377-96.

5. Pleis JR, Lethbridge-Cejku M. Summary health statistics for US adults: National Health Interview Survey. Vital Health Stat 2006;10:1-153.

6. Voerman B, Visser A, Fischer M, Garssen B, van Andel G, Bensing J. Determinants of participation in social support groups for prostate cancer patients. Psychooncology 2007;16:1092-9.

7. Rheuma-schweiz.ch. Swiss Association of Rheumatology Online Resources. <www.rheuma-schweiz.ch> (Accessed on??).

8. Winkelman WJ, Chun Wei C. Provider-sponsored virtual communities for chronic patients: Improving health outcomes through organizational patient-centred knowledge management. Health Expect 2003;6:352-8.
The practical implications of our study lie first of all in understanding the circumstances under which online social support could work more effectively. This is important not only for the patients but also for those who are planning and aiming to provide social support online. Interactive online applications can be considered a promising option for policymakers, albeit one that would supplement rather than supplant other forms of support in the health system. However, it is crucial to acknowledge that online social support works only when it addresses the specific needs of the disease in question. Moreover, our study highlighted the importance of interaction with health professionals, seen as the most reliable source of information and support. All of our patients appreciated the availability of experts for the type of communication that is often not possible during normal medical consultations $(75,76)$. Of course, this somewhat offsets the cost advantages of online social support. If tools like Oneself hinge on extensive involvement of doctors, rather than operating primarily as spaces in which patients support one another, then they become a less economical option.

Finally, the results of our study should be considered in light of some limitations. While we attempted to minimize selection bias, it is inevitable that our sample of interviewees was skewed toward those more willing to talk about their experiences; hence, we have fewer insights into the reactions and experiences of the most reticent patients. In this light, we should acknowledge that our sample might not be perfectly and enough diversified in respect to some aspects. It is likely that, among users who agreed to participate, there was a high proportion of people who were positively impressed or specifically interested in Oneself and its interactive features. Future research would be useful, including larger sample size and comparing people with different experiences with the online tool.

The second limitation concerns generalizability to other diseases. The nature of RA may be such that patients have particular need of practical support from the major sources (such as family and doctors) and less need of interaction and emotional support from sources such as online groups. Life-threatening or severely stigmatized diseases, such as cancer or AIDS, are perhaps more likely to send patients to additional or anonymous arenas such as online support groups (1). Another generalizability issue concerns the age profile of sufferers. Given that older individuals are generally both less familiar with and less trusting of online communication, we can expect the utility of virtual social support to vary widely across different diseases.

FUNDING AND ACKNOWLEDGEMENTS: The authors thank the Swiss National Science Foundation for the financial support of this study (grant number PDFMP1_13511411), as well as the Lega Ticinese per la Lotta contro il Reumatismo and patients' willingness to participate in the studies embodied in this project.
9. Madara EJ. The mutual-aid self-help online revolution. Soc Policy 1997;27:20-6.

10. Lepore SJ, Evans GW, Schneider ML. Dynamic role of social support in the links between chronic stress and psychological distress. J Pers Soc Psychol 1991;61:899-909.

11. Krokavcova M, van Dijk JP, Nagyova I, et al. Social support as a predictor of perceived health status in patients with multiple sclerosis. Patient Edu Couns 2008;73:159-65.

12. Helgeson VS. Social support and quality of life. Qual Life Res 2003;12:25-31.

13. House JS, Landis KR, Umberson D. Social relationships and health. Science 1988;241:540-5.

14. Lee S-YD, Arozullah AM, Cho YI. Health literacy, social support and health: A research agenda. Soc Sci Med 2004;58:1309-21

15. Zimet G, Dahlem N, Zimet S, Farley G. The multidimensional scale of perceived social support. J Pers Assess 1988;52:30-41.

16. Clara IP, Cox BJ, EnnsMW, Murray LT, Torgrudc LJ. Confirmatory factor analysis of the multidimensional scale of perceived social support in clinically distressed and student samples. J Pers Assess 2003;81:265-70.

17. Johnson VR, Jacobson KL, Gazmararian JA, Blake SC. Does social support help limited-literacy patients with medication adherence? 
A mixed methods study of patients in the Pharmacy Intervention for Limited Literacy (PILL) Study. Patient Educ Couns 2010;79:14-24.

18. Antonucci TC, Ajrouch KJ, Janevic MR. The effect of social relations with children on the education health link in men and women aged 40 and over. Soc Sci Med 2003;56:949-60.

19. Strating MM, van Schuur WH, Suurmeijer TP. Contribution of partner support in self-management of rheumatoid arthritis patients. An application of the theory of planned behavior. J Behav Med 2006;29:51-60.

20. Courneya KS, Plotnikoff RC, Hotz SB, Nicholas JB. Social support and the theory of planned behavior in the exercise domain. Am J Health Behav 2000;24:300-8.

21. Vilhjalmsson R. Life stress, social support and clinical depression: A reanalysis of the literature. Soc Sci Med 1993;37:331-42.

22. Thoits PA. Stress, coping, and social support processes: Where are we? What next? J Health Soc Behav 1995;Spec No:53-79.

23. Froidevaux Y, Täube VG. Utilisation d'Internet dans les ménages en Suisse. Résultats de l'enquête 2004 et indicateurs. [Use of the Internet in Swiss households. Results of the 2004 survey and indicators]. Neuchâtel: Office fédéral de la statistique, 2006.

24. Klemm P, Nolan MT. Internet cancer support groups: Legal and ethical issues for nurse researchers. Oncol Nurs Forum 1998;25:673-6.

25. Werner A, Malterud K. It is hard work behaving as a credible patient: Encounters between women with chronic pain and their doctors. Soc Sci Med 2003;57:1409-19.

26. Brashers DE, Goldsmith DJ, Hsieh E. Information seeking and avoiding in health contexts. Hum Commun Res 2002;28:258-71.

27. Hesse BW, Nelson DE, Kreps GL, et al. Trust and sources of health information. The impact of the internet and its implications for health care providers: Findings from the first Health Information National Trends Survey. Arch Intern Med 2005;165:2618-24.

28. Eysenbach G. Patient-to-patient communication: Support groups and virtual communities. In: Lewis D, Eysenbach G, Kukafka R, Stavri PZ, Jimison H, eds. Consumer Health Informatics. New York: Springer, 2005:97-106.

29. Murray E, Burns J, See Tai S, Lai R, Nazareth I. Interactive Health Communication Applications for people with chronic disease. Cochrane Database Syst Rev 2005;(4):CD004274.

30. Van Uden-Kraan CF, Drossaert CH, Taal E, Shaw BR, Seydel ER, Van de Laar MA. Participation in online patient support groups endorses patients' empowerment. Patient Educ Couns 2009;74:61-9.

31. Van Uden-Kraan CF, Drossaert CH, Taal E, Shaw BR, Seydel ER, Van de Laar MA. Empowering processes and outcomes of participation in online support groups for patients with breast cancer, arthritis and fibromyalgia. Qual Health Res 2008;18:405-17.

32. Hausmann LRM, Parks A, Youk AO, Kwoh, CK. Reduction of bodily pain in response to an online positive activity intervention. J Pain 2014;15:560-7.

33. Schulz PJ, Nakamoto K. Health literacy and patient empowerment in health communication: The importance of separating conjoined twins. Patient Educ Couns 2013;90:4-11.

34. Caiata-Zufferey M, Schulz PJ. Self-management of chronic low back pain: An exploration of the impact of a patient-centered website. Patient Educ Couns 2009; 77:27-32.

35. Davison KP, Pennebaker JW, Dickerson SS. Who talks? The social psychology of illness support groups. Am Psychol 2000;55:205-17.

36. Schulz PJ, Rubinelli S, Zufferey MC, Hartung U. Coping with chronic low back pain: Designing and testing the online tool Oneself. J Comput Mediat Commun 2010;15:625-45.

37. Han JY, Eunkyung K, Pingree R. Factors associated with use of interactive cancer communication system: An application of the comprehensive model of information seeking. J Comput Mediat Commun 2010;15:367-88.

38. Leydon GM, Boulton M, Moynihan C, et al. Cancer patients' information needs and information seeking behaviour: In depth interview study. Inf Pract 2009;320:909-13.

39. Dutta MJ, Feng H. Health orientation and disease state as predictors of online health support group use. Health Comm 2007;22:181-9.

40. Dutta-Bergman MJ. Health attitudes, health cognitions, and health behaviors among Internet health information seekers: Populationbased survey. J Med Internet Res 2004;6:1-7.

41. Berger M, TH Wagner LC. Baker: Internet use and stigmatized illness. Soc Sci Med 2005;8:1821-7.

42. Buchanan H, Coulson NS. Accessing dental anxiety online support groups: An exploratory qualitative study of motives and experiences. Patient Educ Couns 2007;66:263-9.
43. Greenhalgh T, Wood GW, Bratan T, Stramer K, Hinder S. Patients' attitudes to the summary care record and Health Space: Qualitative study. BMJ 2008;336:1290-5.

44. Kostova Z, Caiata-Zufferey M, Schulz PJ. The impact of social support on the acceptance process among RA patients: A qualitative study. Psychol Health 2014;29:1283-302.

45. Allam A, Kostova Z, Nakamoto K, Schulz, PJ. The effect of social support features and gamification on a Web-based intervention for rheumatoid arthritis patients: randomized controlled trial. J Med Internet Res 2015;17:e14

46. Suurmeijer TH, Van Sonderen FL, Krol B, Doeglas DM, Van Den WJ, Heuvel R Sanderman. The relationship between personality, supportive transactions and support satisfaction, and mental health of patients with early rheumatoid arthritis. Results from the Dutch part of Euridiss Study. Soc Ind Res 2005;73:179-97.

47. Strauss A, Corbin J. Basics of Qualitative Research: Grounded Theory Procedures and Techniques. Newbury Park: Sage, 1990.

48. Mays N, Pope C. Rigour and qualitative research. BMJ 1995;311:109-12.

49. Van Uden-Kraan CF, Drossaert CH, Taal E, Shaw BR, Seydel ER, Van de Laar MA. Self-reported differences in empowerment between lurkers and posters in online patient support groups. J Med Int Res. 2008;10:e18

50. van de Poll-Franse LV, van Eenbergen MC. Internet use by cancer survivors: Current use and future wishes. Support Care Cancer 2008;47:2188-94.

51. Bauman LJ, Gervey R, Siegel K. Factors associated with cancer patients' participation in support groups. J Psychosoc Oncol 1992;10:1-20.

52. Grande GE, Myers LB, Sutton SR. How do patients who participate in cancer support groups differ from those who do not? Psychooncology 2006;15:321-34.

53. Voerman B, Visser A, Fischer M, Garssen B, van Andel G, Bensing J. Determinants of participation in social support groups for prostate cancer patients. Psychooncology 2007;16:1092-9.

54. Shaw BR, DuBenske LL, Han JY, et al. Antecedent characteristics of online cancer information seeking among rural breast cancer patients: An application of the cognitive-social health information processing (C-SHIP) model. J Health Comm 2008;13:389-408.

55. Van Uden-Kraan CF, Drossaert CH, Taal E, Shaw BR, Seydel ER, Van de Laar MA. Determinants of engagement in face-to-face and online patient support groups. J Med Internet Res 2011;13:e106.

56. Ammann Y. Rapport sur les principaux résultats du sondage: Santé et information. Lausanne: Service cantonal de recherche et d'information statistiques du Canton de Vaud (SCRIS), 2000.

57. Jeannot J, Froehlich F, Wietlisbach V, Burnand B, Terraz O, Vader J. Patient use of the Internet for health care information in Switzerland. Swiss Medical Weekly 2004;134:307-12.

58. Seematter-Bagnoud L, Santos-Eggimann B. Sources and level of information about health issues and preventive services among young-old persons in Switzerland. Int J Public Health 2007;52:313-6.

59. Preece J, Nonnecke B, Andrews D. The top five reasons for lurking: improving community experiences for everyone. Comput Human Behav 2004;20:201-23.

60. Winzelberg A. The analysis of an electronic support group for individuals with eating disorders. Comput Human Behav 1997;13:393-407.

61. Finfgeld DL. Therapeutic groups online: The good, the bad, and the unknown. Issues Ment Health Nurs 2000;21:241-55.

62. McCracken LM, Eccleston C. A comparison of the relative utility of coping and acceptance- based measures in a sample of chronic pain sufferers. Eur J Pain 2006;10:23-9.

63. Viane I, Crombez G, Eccleston C, et al. Acceptance of pain is an independent predictor of mental well-being in patients with chronic pain: Empirical evidence and reappraisal. Pain 2003;106:65-72.

64. Caiata-Zufferey M, Schulz PJ. Potentialities and limits of Internet health communication in chronic care: Results from a qualitative study. Social Semiotics 2010;20:61-75.

65. Waugh OC, Byrne DG, Nicholas MK. Internalized stigma in people Living with chronic pain. J Pain 2014;15:550.e1-10

66. Grande GE, Myers LB, Sutton SR. How do patients who participate in cancer support groups differ from those who do not? Psychooncology 2006;15:321-34. 
67. Finfgeld DL. Therapeutic groups online: The good, the bad, and the unknown. Issues Ment Health Nurs 2000;21:241-55.

68. Finn J. An exploration of helping processes in an online self-help group focusing on issues of disability. Health Soc Work 1999;24:220-31.

69. Salem DA, Bogat GA, Reid C. Mutual help goes on-line. J Community Psychol 1997;25:189-207.

70. Keijser WA. Online gezondheidsinformatie en lotgenotencontact. Utrecht: Wacomed, 2005.

71. Payne V, Kiel JM.Web-based communication to enhance outcomes: A case study in patient relations. J Healthc Inf Manag 2005;19:56-63.

72. Skelton AM, Murphy EA, Murphy RJL, O'Dowd N. Patient education for low back pain in general practice. Patient Educ Couns 1995;25:329-34.
73. Skelton AM, Murphy EA, Murphy RJL, O'Dowd N. Patients' view of low back pain and its management in general practice. Br J Gen Pract 1996;46:153-156.

74. Weissenberger C, Jonassen S, Beranek-Chiu J, et al. Breast cancer: Patient information needs reflected in English and German websites. Br J Cancer 2004;91:1482-7.

75. Ogden JK, Bavalia M, Bull S, et al. "I want more time with my doctor". A quantitative study of time and the consultation. Fam Pract 2004;21:479-83.

76. Patel H. Why doctors have less time for patients. J R Soc Med 2002;95:604-5. 


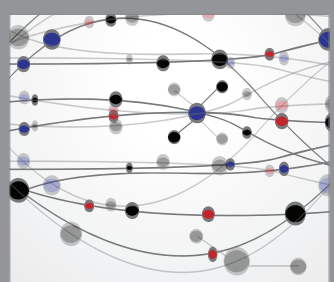

The Scientific World Journal
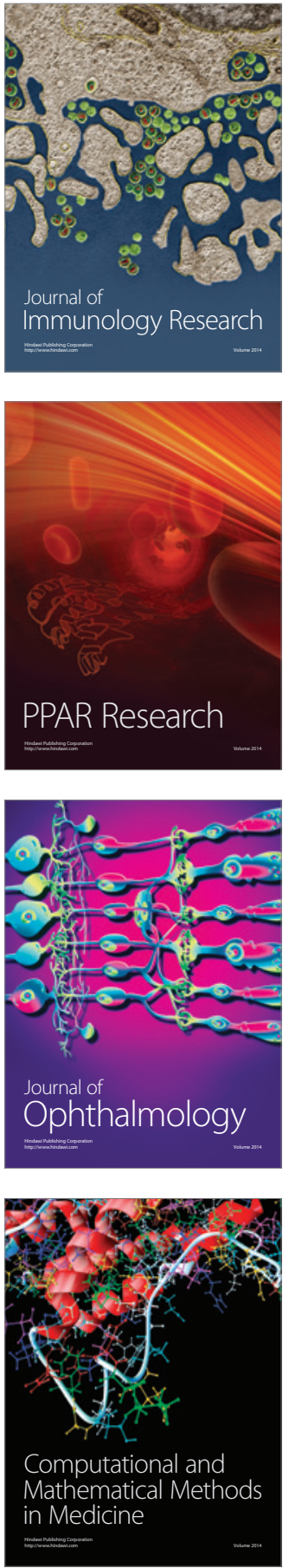

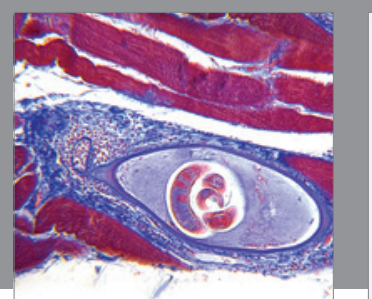

Gastroenterology Research and Practice

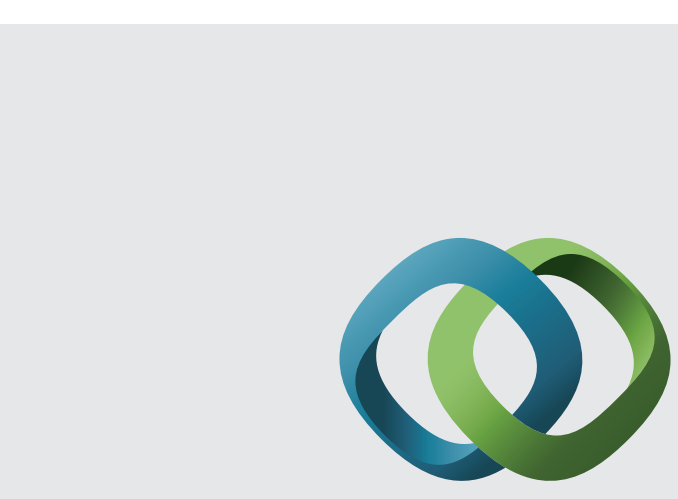

\section{Hindawi}

Submit your manuscripts at

http://www.hindawi.com
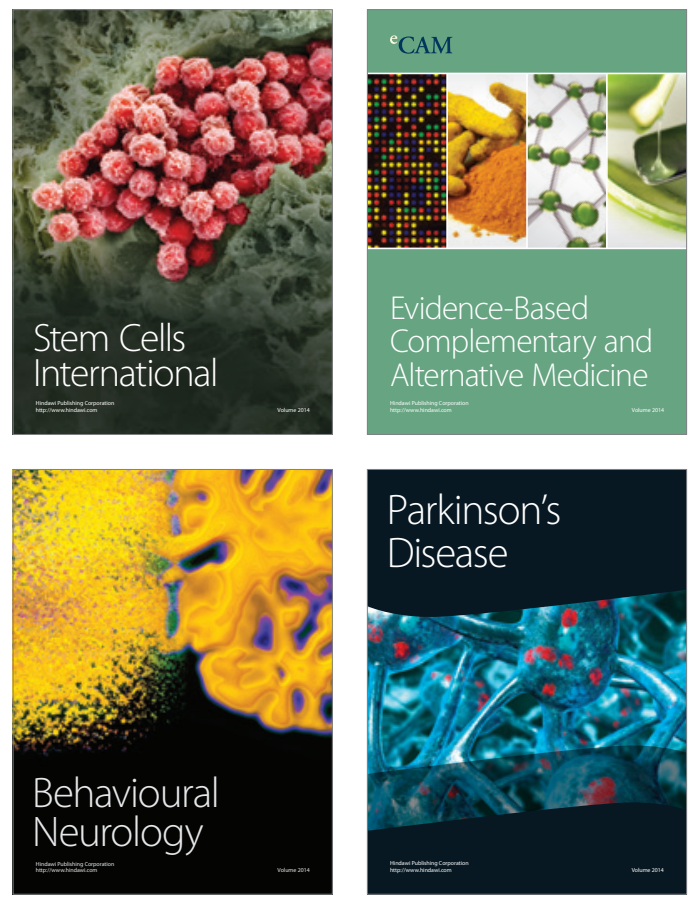
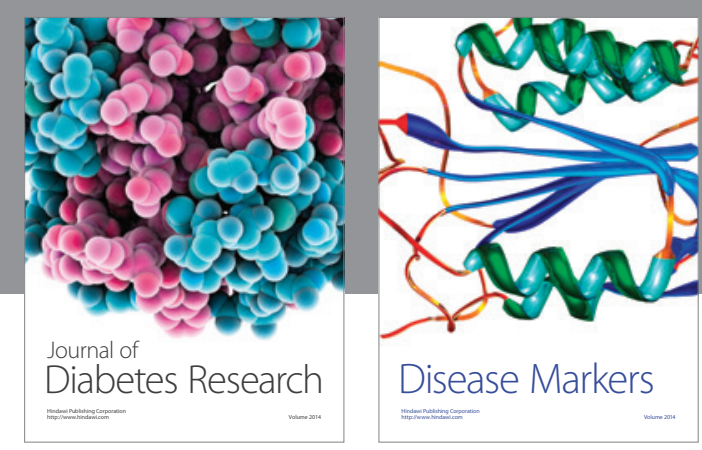

Disease Markers
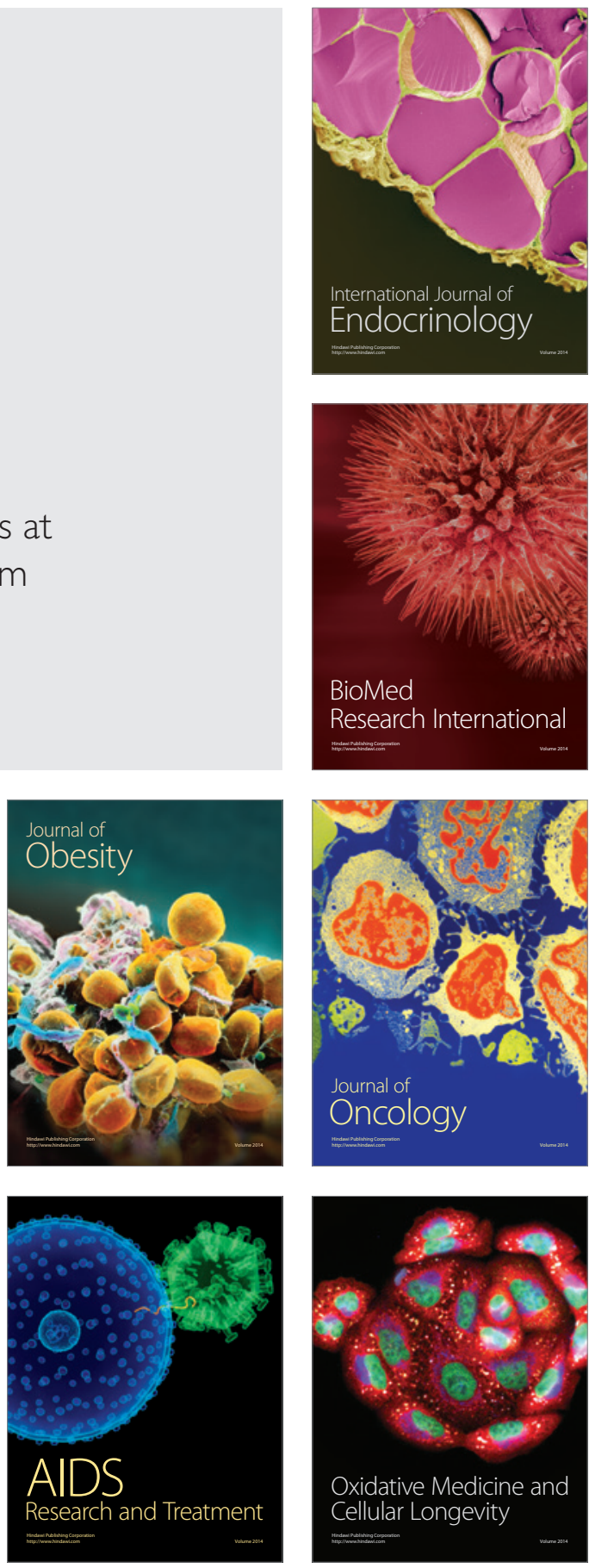